\title{
A Familial Case of Hereditary Angioneurotic Edema in Japan
}

\author{
Hiroshi Yamato, Yasuhide Nakashima, Kenichi Ninomiya, Shugo Sakurai and Akio Kurorwa
}

\begin{abstract}
A 53-year-old man was admitted with impairment of breathing following laryngeal edema. Serum levels of $\mathrm{CH}_{50}(22 \mathrm{U} / \mathrm{ml}), \mathrm{C} 4(3 \mathrm{mg} / \mathrm{dl}), \mathrm{C} 1-\mathrm{INH}$ protein $(10.6 \mathrm{mg} / \mathrm{dl})$ and $\mathrm{C} 1-\mathrm{INH}$ activity (LT 25\%) were low. Complement study of the patient's family members revealed that he was one of 5 patients in 3 generations with hereditary angioneurotic edema (HANE). Administration of the androgen derivatives Danazol $(600 \mathrm{mg} /$ day $)$ and Oxymetholone $(30 \mathrm{mg} /$ day $)$ effectively increased serum levels of C1-INH activity and C4. Though eruption and hepatic dysfunction attributable to administration of the drugs appeared, these side effects improved after withdrawal of the drugs. Subsequently, the treatment with Danazol at a low dose $(100 \mathrm{mg} / \mathrm{day})$ was resumed, and the patient has had no episodes of edema for the past 3 years. Regarding the familial cases of HANE, fewer than 20 have been reported in Japan.
\end{abstract}

(Internal Medicine 31: 353-356, 1992)

Key words: C1-INH, anabolic steroid, edema attack

\section{Introduction}

Hereditary angioneurotic edema (HANE) is an autosomal dominant hereditary disease in which there is a decrease or defect in $\mathrm{C} 1$-inactivator protein (C1-INH), which is an inhibitor of the first component of complement in the serum, and/or a decrease in C1-INH activity $(1-4)$.

The pathophysiology of this disease is characterized by recurrent spontaneous episodes of transient edema of the mucosa, skin or subcutaneous tissue with remission at irregular intervals. A variety of symptoms including cerebral nervous symptoms, ileus and anuria may appear depending on the site of onset of edema. Patients may die because of laryngeal obstruction caused by laryngeal edema.

We report here a familial case of HANE in Japan and the effect of anabolic steroids to increase the C1-INH activity.

\section{Patient Profile}

A 53-year-old man had experienced several episodes of transient edema since the age of 20 , in which the edema appeared at lightly bruised areas on the extremities and then disappeared spontaneously within several days. At the age of 50 he had developed edema of the face and neck accompanied by mild dyspnea after biting his lower lip, for which he had been successfully treated within 2 days with $1,000 \mathrm{mg}$ of hydrocortisone by a private physician.

On March 15, 1987, he had consulted a private physician for tongue edema which had developed without obvious provocation, for which he was given antihistamines and $600 \mathrm{mg}$ hydrocortisone in one dose. Within several hours the edema had extended to the oral mucosa and neck, causing dyspnea. He was intubated and transferred to ICU at our hospital for further treatment.

The patient's family pedigree is shown in Fig. 1. His father (I-1, Fig. 1), who had died of heart disease, had occasionally experienced episodic swelling of the extremities of unknown cause. The patient's sister (II-4, Fig. 1), age 46, has had episodic swelling of the extremities and face every 3 or 4 years since the age of about 21, although she has had no edema since the age of 40. The patient's elder daughter (III-1, Fig. 1), age 23, has experienced episodic swelling of the extremities and face several times since the age of about 20 .

Physical examination at admission revealed the following: heart rate was $70 / \mathrm{min}$ and regular; blood pressure was $100 / 70 \mathrm{mmHg}$; and respiration rate under intubation was 16 breath/min and regular. The neck edema was marked, and the scrotum and right foot showed similar

From the Second Department of Internal Medicine, University of Occupational and Environmental Health, Japan, School of Medicine, Kitakyushu

Received for publication December 19, 1990; Accepted for publication July 31, 1991

Reprint requests should be addressed to Yasuhide Nakashima, M.D., the Second Department of Internal Medicine, University of Occupational and Environmental Health, Japan, School of Medicine, Iseigaoka, Yahatanishiku, Kitakyushu, 807, Japan 


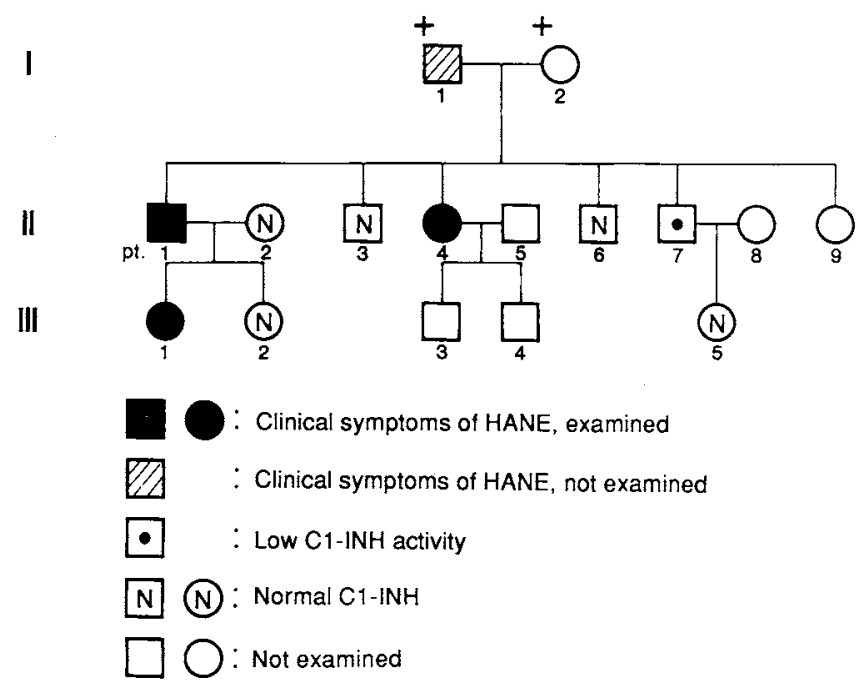

Fig. 1. Family pedigree shows that there are 5 patients of HANE in 3 generations.

edema. The palpebral conjunctiva was free of anemia or jaundice. The heart sound was clear; no rales were heard. The liver, spleen and superficial lymph nodes were not palpable. Neurological examination revealed no abnormal findings. The patient's serum levels of $\mathrm{CH}_{50}$ $(22 \mathrm{U} / \mathrm{ml})$ and $\mathrm{C} 4(3 \mathrm{mg} / \mathrm{dl})$ were both markedly decreased. C1-INH activity was $<25 \%$, and C1-INH protein was $10.6 \mathrm{mg} / \mathrm{dl}$, also markedly decreased. However, serum level of $\mathrm{C} 3$, at $73 \mathrm{mg} / \mathrm{dl}$, was within normal limits.

Figure 2 shows the treatment schedule and clinical course. Following steroid pulse therapy with $1,000 \mathrm{mg}$ of methylprednisolone for the first three days after admission, edema subsided sufficiently to permit extubation. Subsequently, prednisolone was administered at $20 \mathrm{mg}$, and the dosage was tapered over the following ten days.

HANE was diagnosed on the basis of the clinical symptoms, family history, and markedly decreased serum C1-INH activity and C1-INH protein and C4 levels. Results of familial serological study are shown in Table 1. After the definite diagnosis was established, the patient was treated with $600 \mathrm{mg} /$ day of Danazol, an androgen derivative which is effective in increasing the serum C1INH activity and the $\mathrm{C} 4$ level. However, after three days of Danazol therapy at $600 \mathrm{mg} /$ day, he developed an adverse reaction to Danazol including eruptions. Consequently, Danazol was discontinued after $300 \mathrm{mg} /$ day for three days and replaced with $30 \mathrm{mg} /$ day of Oxymetholone. As a result, C1-INH activity increased from its pre-treatment value of less than $25 \%$ to $33-38 \%$, and $\mathrm{C} 4$ level increased from $7-8 \mathrm{mg} / \mathrm{dl}$ to $21 \mathrm{mg} / \mathrm{dl}$. But he developed liver dysfunction, and Oxymetholone was discontinued. Subsequently, Danazol at a low dose $(100 \mathrm{mg} /$ day $)$ was resumed. The patient has had no episodes of edema during 3 years of follow-up at an outpatient clinic.

\section{Discussion}

There have been fewer than 20 cases of familial HANE reported in Japan, and the present case is a new one. HANE manifests as an autosomal-dominant hereditary trait, and transient localized edema occurs with or without stimulation by any obvious provocation such as trauma, inflammation, mechanical stimulation, emotional stimulation of the adrenocortical sympathetic system or exposure to cold outdoor air (3). Symptoms are induced by a deficiency of C1-INH activity in the serum due to a decrease or defect in $\mathrm{C} 1-\mathrm{INH}$ protein itself

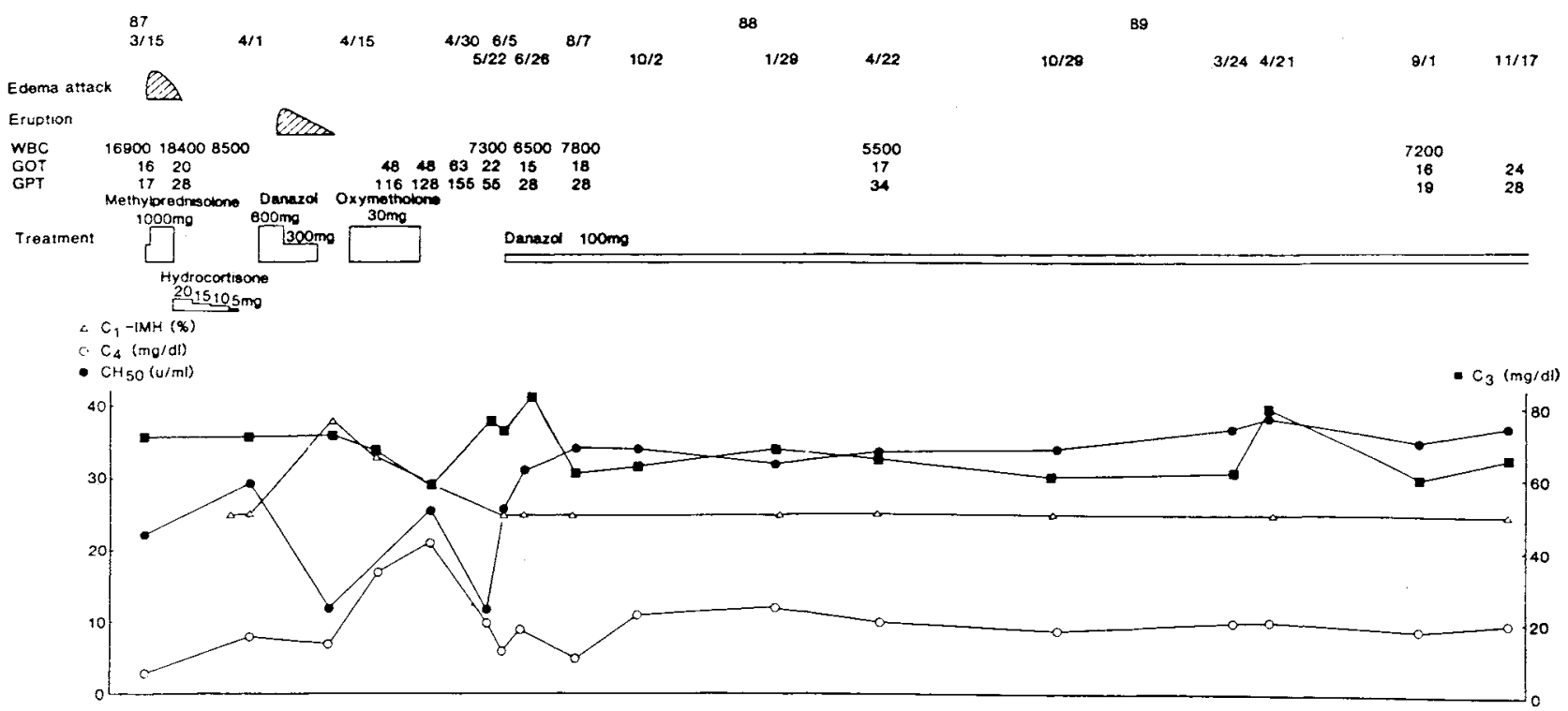

Fig. 2. Clinical course 
(Type 1) or a decrease in inhibitory activity (Type 2). Since Type $1 \mathrm{HANE}$ is a heterozygous deficiency state, the synthesis of normal C1-INH would be expected to be approximately half that of normal individuals. But the fractional catabolic rate of the normal protein is elevated in patients to a degree consistent with the reduction in C1-INH levels below $50 \%$ of normal. Because of the diminished level of C1-INH, the $\mathrm{Cl}$ activation that occurs during the attack results in consumption of its substrates, $\mathrm{C} 2$ and $\mathrm{C} 4$, and this results in diminished serum concentrations of these proteins. C1-INH inhibits not only the activities of $\mathrm{C} 1 \mathrm{r}$ and $\mathrm{C} 1 \mathrm{~s}$, but also those of kallikrein, coagulation factor XI, plasmin, Hageman factor, and its degradation product in the fibrinolytic system. The decrease in C1-INH activity seen in HANE is believed to occur through the following mechanisms. The coagulation, fibrinolytic, and kallikrein-kinin systems are activated and the systems then act on each other with a resultant decrease in C1-INH activity, inducing edema (5-7).

Because no definitive diagnosis could be established when the patient visited his private physician and when he was transfered to our hospital, he was treated with antihistamines and steroid pulse therapy under intratracheal intubation at the acute stage. However, the improvement in edema in this case seemed to be spontaneous.

Observation that $\mathrm{C} 1-\mathrm{INH}$ and $\mathrm{C} 4$ levels decreased during the acute phase of episodic edema and analysis of family history led to the subsequent diagnosis of HANE. Because both the activity and serum level of C1-INH protein were reduced, this familiy was diagnosed as having Type 1 HANE.

Similar edema had appeared in his father, sister, and elder daughter. Decreases in C1-INH activity were observed in his sister, elder daughter, and younger brother (Table 1). These findings showed that HANE was expressed in 5 members of 3 generations of this family as an autosomal dominant trait. The absence of edema in his younger brother supports the view of Kodama et al(2) that individuals having similar hereditary predisposition show different reactions to similar provo- cation.

Increasing the serum level of $\mathrm{C} 1-\mathrm{INH}$ by an injection of C1-INH is effective for pre-existing edema in HANE, and hormone preparations including Danazol (8) and proteolytic inhibitors such as $\varepsilon$-amino caproic acid, Tranexamic acid, Aprotinin, and Suramin, are known to prevent edema $(9-12)$. The mechanisms by which androgens exert their effect on C1-INH levels remain to be defined, although presumably synthesis by the liver is enhanced $(3,6)$.

Though the improvement in edema in this case seemed to be spontaneous, Danazol at a dose of $600 \mathrm{mg} /$ day was attempted as a long-term prophylactic measure. However, eruption attributable to the drug appeared; Danazol was then replaced with Oxymetholone at a dose of $30 \mathrm{mg} /$ day. C1-INH activity and C4 level increased after institution of this therapy, which would suggest the efficacy of the anabolic steroid. However, hepatic dysfunction attributable to Oxymetholone appeared, and the drug was withdrawn. Subsequently, Danazol was resumed at a low dose ( $100 \mathrm{mg} /$ day $)$, and the patient has had no episode of edema during the past 3 years. During the period of low-dose therapy with Danazol, however, the increases in $\mathrm{C} 1-\mathrm{INH}$ activity and $\mathrm{C} 4$ level were minimal. This patient has had no HANE attack during 3 years of maintenance on Danazol $(100 \mathrm{mg} /$ day $)$ after discharge. However, as he has a history of a HANE attack every several years, it is very difficult to discuss whether the absence of a HANE attack for 3 years in this case would be due to the prophylactic effect of Danazol or simply to the natural course. Follow-up must be continued.

\section{References}

1) Donaldson VH, Evans RR. A biochemical abnormality in hereditary angioncurotic edema. Am J Med 35: 37, 1963.

2) Kodama J, Uchida K, Yoshimura S, et al. Studies of four Japanese families with hereditary angioneurotic edema: simultaneous activation of plasma protease systems and exogenous triggering stimuli. Blut 49: 405, 1984.

Table 1. Laboratory Findings

\begin{tabular}{llccccc}
$\begin{array}{l}\text { Patient } \\
\text { code } \\
\text { number }\end{array}$ & $\begin{array}{c}\text { Relation to } \\
\text { the patient }\end{array}$ & $\begin{array}{c}\mathrm{C}_{1} \text {-INH activity } \\
\% \\
(80 \sim 125)\end{array}$ & $\begin{array}{c}\mathrm{C}_{4} \\
\mathrm{mg} / \mathrm{dl} \\
(12 \sim 39)\end{array}$ & $\begin{array}{c}\mathrm{C}_{3} \\
\mathrm{mg} / \mathrm{dl} \\
(59 \sim 120)\end{array}$ & $\begin{array}{c}\mathrm{CH}_{50} \\
\text { units/ml } \\
(30 \sim 40)\end{array}$ & HANE \\
\hline II-1 & Patient & $<25$ & 8 & 73 & 29.3 & + \\
II-2 & Wife & 89 & 37 & 91 & 39.3 & $\mathrm{ND}$ \\
II-3 & Brother & 101 & 16 & 60 & $\mathrm{ND}$ & $\mathrm{ND}$ \\
II-4 & Sister & $<25$ & $<5$ & 65 & $<12$ & + \\
II-6 & Brother & 108 & 24 & 71 & 31.2 & $\mathrm{ND}$ \\
II-7 & Brother & $<25$ & 9 & 72 & 27.6 & + \\
III-1 & First daughter & $<25$ & 12 & 69 & $\mathrm{ND}$ & + \\
III-2 & Second daughter & 91 & 14 & 65 & 26.5 & $\mathrm{ND}$ \\
III-3 & Niece & 124 & 40 & 99 & $\mathrm{ND}$ & $\mathrm{ND}$ \\
\hline
\end{tabular}

ND, not detectable 


\section{Yamato et al}

3) Davis AE, III. C1 inhibitor and hereditary angioneurotic edema. Ann Rev Immunol 6: 595, 1988.

4) Nicholas AS, Irma G. Angioedema associated with complement abnormalities in: Dermatology in General Medicine: section 19, chapter $106,1293-1300$

5) Cungno $M$, Nuijens $J$, Hack $E$, et al. Plasma levels of $C 1$ inhibitor complexes and cleaved $\mathrm{C} 1$ inhibitor in patients with hereditary angioneurotic edema. J Clin Invest 85: 1215, 1990.

6) Davis AE, III. Hereditary and acquired deficiencies of $\mathrm{C} 1$ inhibitor. Immunodeficiency Reviews 1: 207, 1989.

7) Donaldson $\mathrm{VH}$, Wagner $\mathrm{CJ}$, Tsuei $\mathrm{B}$, et al. Interactions of plasma kallikrein and $\mathrm{C} 1 \mathrm{~s}$ with normal and dysfunctional C1inhibitor proteins from patients with hereditary angioneurotic edema: Analytic gel studies. Blood angioneurotic edema: Analytic gel studies. Blood 69: 1096, 1987.
8) Ghebrehiwet B, Silverberg M, Kaplan AP. Activation of the classical pathway of complement by Hageman factor fragment. J Exp Med 153: 665, 1981.

9) Gelfand JA, Sherins RJ, Alling DW, Frank MM. Treatment of hereditary angioneurotic edema with Danazol. N Engl J Med 295: $1444,1976$.

10) Gadek JE, Hosea SW, Gelfand JA, Frank MM. Replacement therapy in hereditary angio edema: Successful treatment of acute episodes of angioedema with partly purified C1 inhibitor. N Engl J Med 302: 542, 1980.

11) Frank MM, Sergent JS, Kane MA, et al. Epsilon aminocaproic acid therapy of hereditary angioneurotic edema: A double-blind study. N Engl J Med 286: 808, 1972.

12) Sheffer AL, Austen KF, Rosen FS. Tranexamic acid therapy in hereditary angioneurotic edema. N Engl J Med 287: 452, 1972. 